\title{
Limitations and perspectives of the physiology laboratory PhysioEx V9.1 during single-center Peruvian medical education
}

\author{
Jeel Moya-Salazar ${ }^{1,2 *}$ \\ ${ }^{1}$ School of Human Medicine, Faculty of Health Sciences, Norbert Wiener University, Lima, Peru \\ ${ }^{2}$ School of Medical Technology, Faculty of Medicine and Health Sciences, Universidad Privada San Juan Bautista, Ica, Peru
}

\begin{abstract}
Introduction: Virtual reality is a controversial tool in medical education; it has previously been shown to be very useful in anatomy and physiology.

Objective: to evaluate the physiology simulation laboratory PhysioEx v9.1 during the course of Human Morphophysiology at a private university in Lima, Peru.

Methods: This cross-sectional study was developed in two stages: the first, under the critical approach of software analysis, and the second, with a structured survey aimed at Human Medicine students on simulation. The study instrument was subdivided into two parts with 17 questions (15 closed and 2 open). The first surveyed the know-how of the previous three weeks of simulation, and the second, on the Technologies Applied to Health Communication and a satisfaction scale of the study program and the simulator.

Results: Our findings show a high performance of the simulator in the approach to cellular physiology, where $\sim 70 \%$ and $\sim 60 \%$ of students understood respectively passive and active transport, and membrane potential and electrical transmission. The experience was rated as relevant (35\%), satisfactory (55\%), and indicative (77\%). Forty-five percent considered the English language as the major limitation, followed by inaccessibility in other spaces such as their homes or work centers (20\%). The main advantages were graphics (45\%) and ease-of-use (25\%). Thirty percent do not believe that the experience allows consolidating the studies of medicine and $78 \%$ experience inattention by the teacher.
\end{abstract}

Conclusions: the evaluation of the simulator allowed knowing its main advantage and reticence (the English language) within a new educational experience in Peruvian students.

\section{Introduction}

As pointed out by the fourth goal of the Sustainable Development Goals of the United Nations, must ensure quality, inclusive, sustainable, and equitable education between industrialized countries and middle-and-low-income countries [1,2]. Pro ómnibus to undertake proposed against this contingency by 2030 , Peru must overcome various governmental and non-governmental challenges at all levels of education. Moreover, when various international assessments reflect our limited educational system, and therefore a poor education with low social, scientific, and technological information [1-6].

Apparently the efforts made by the Ministry of Education have not been enough to promote quality education. This orthodox support of education today is mainly reflected in the structure of primary and secondary school's curricula, the formats exams for university admission, and results from the world rankings on educational quality that put us far from optimal [5]. This disadvantage notion about education is not new, in fact, have located reflections from $\sim 30$ years as stated in the book Ethics, Medicine and Society [7].

University education, unlike elementary and higher education, has the responsibility to train professional ethics and morally aware of their roles, responsibilities, and privileges. These professionals form the economically active source and whose collective fall our future and our wellbeing. This responsibility usually remakes even more in students of
Health Sciences, and mainly in the career of Human Medicine (HM), highly plaintiff and defendant profession that promotes annual ranking of 19 000 graduates in medicine and surgery in the United States [8].

From Greek schools to current applications of robotics and cybernetics, medical education has been the main purpose and challenge of universities that assume provocationem to form humanitarian and assistance physicists. Many of these medical schools ( $>2600$ training schools worldwide) preserved ancient teaching tools, such as dissection of corpses, the use of experimental animals, etc. [9]. However, many globally recognized institutions have accepted information technology and communications (ICT) as useful tools in modern medical training.

We understand that not all subject teaching broad medical field can adopt ICTs, but others are enriched by the benefits generated by the use of modern tools that reduce fatigue of teachers, increase student attention, understanding and change the teaching approach focused on

${ }^{\star}$ Correspondence to: School of Human Medicine, Faculty of Health Sciences, Norbert Wiener University, Lima, Peru, E-mail: jeel.moya@upsjb.edu.pe

Key words: software, medical education, anatomy, cell physiological phenomena, Peru

Received: September 21, 2019; Accepted: September 27, 2019; Published: September 30, 2019 
the teacher, and allow the simulation of clinical, biological, anatomical contexts, and facilitate the visualization of tangible components that have often been displayed in graphs, drawings or human or animal corpses. Take me told to refer the interest of anatomy, morphology, physiology, chemistry, and semeiology by these tools boom in this technological era.

For example, understanding human anatomy, science that studies the structure of living organisms and human physiology, science that studies the normal body functions and parts (both in health and in disease) are two key pieces of training medical. Knowing how these tools can be useful, the benefits of its use and risks of their abuse must be habitual activities for medical schools that have managed to "modernize" their teaching. In view of the progress of virtual reality, artificial intelligence, robotics, and settlement of the technological age, these educational activities will directly affect novice medical students who use their native technology today, and, at the same time, it will be a challenge for technological immigrants who must adapt to this environment $[10,11]$.

We aimed to evaluate the physiology laboratory simulation PhysioEx v9.1 (Pearson Education, London, UK) at the Human Morphophysiology I (HMI) sessions for medical students at Universidad Norbert Wiener in Lima, Peru.

\section{Methods}

A cross-sectional study was conducted during HMI sessions in two stages: first, under the critical approach analysis software [12], and second, the results of a survey of MHI students (users) were exposed about the simulation lab. In both stages, the results were exposed highlighting the reticence and benefits of the physiology simulation laboratory PhysioEx v9.1.

The study was developed during the 2018-cycle-II at School of Medicine of the Universidad Norbert Wiener. HMI course involves anatomy, physiology, histology, and standard imaging on the secondyear medicine.

\section{Physiology laboratory simulation}

PhysioEx software v9.1 (www.physioex.com) is a laboratory simulation of biochemical processes that consists of 63 activities and twelve physiology laboratory exercises. Simulator activities were developed in groups of $\sim 8$ students on a touch-screen smart SHARP PN-L803C Class Aquos board ${ }^{\circledR}$ (Tokyo, Japan) of 80-inch, LED with local server connection to the university.

The simulator has a manual guide for each of the activities, reason why experiments can be performed as many times as they were required. This interface allowed students to conduct experiments that require highly complex materials, high cost, time and risk to student safety through simulation events and feedback with rapid assessments. Table 1 details the components of the simulation laboratory.

\section{First stage evaluation}

The following evaluation components were included according to the syllabus of the first topics of the course: a) cytology and passive membrane transport, b) membrane active transport, and c) cellular action potential (voltage-dependent transporters). The unit of analysis was the software that was evaluated by 240 students.

During and following of lesson, the limitations and benefits of PhysioEx based on critical analysis software approach were evaluated
Table 1. Components and activities simulation lab PhysioEx v9.1 biochemical processes

\begin{tabular}{|l|l|l|}
\hline $\mathbf{N}$. & Components & Class activities \\
\hline 1 & Transport mechanisms and cellular permeability & 5 activities \\
\hline 2 & Skeletal muscle physiology & 7 activities \\
\hline 3 & Neurophysiology of nerve impulses & 9 activities \\
\hline 4 & Endocrine physiology & 4 activities \\
\hline 5 & Cardiovascular dynamics & 7 activities \\
\hline 6 & Cardiovascular physiology & 5 activities \\
\hline 7 & Mechanism of the respiratory system & 3 activities \\
\hline 8 & chemical and physical processes of digestion & 4 activities \\
\hline 9 & Renal physiology system & 6 activities \\
\hline 10 & Acid-base balance & 4 activities \\
\hline 11 & Blood test & 5 activities \\
\hline 12 & Serologic tests & 4 activities \\
\hline
\end{tabular}

[12]. We were applied the four education's paradigms and these were presented coupled with interaction types that were raised by Squirres and McDougall [13].

\section{Second stage of evaluation}

After the third week of study, a validated structured questionnaire ( $\alpha$-Cronbach $=0.85$ ) was performed. Of the participants, $\sim 80 \%$ have previously studied some technical or university degree linked or not Health Sciences and/or took the course for the second time (previous experience $\sim 6$ months in the use of system). Those who took the HMI course for the second time had experiences with PhysioEx in other previous courses.

The survey instrument was divided into two parts consisting of 17 questions, 15 closed and 2 open. The first surveyed the know-how of the previous three weeks. The second part, about ICT applied in health and a satisfaction scale of curriculum and simulator according to the recommendations of the Government of Navarra [14].

\section{Data analysis}

Descriptive and inferential statistics were used to summarize the main findings. Pearson's test was used to assess inter-observer responses. We consider a $\mathrm{p}<0.05$ and a confidence interval (CI) of $95 \%$ as statistically significant. Data analysis was performed using the statistical analyzer EPIDAT-info v2.0 (Xunta de Galicia, Spain).

\section{Ethics considerations}

The author fulfilled the ethical considerations during the phases of the study, according to the criteria of bioethics.

\section{Results}

\section{First stage}

According to the critical software evaluation approach we described that during the practice of passive transport could verify the relationship between the pore size, expressed in Molecular Weigth Cutt-Off (MWCO) in Daltons, and the size and concentration of each molecule in mili-moles $(\mathrm{mM})$ through exchange experiment solutions. The results are presented in Table 2.

Also, extracurricular activities include the exploration of the limits of the simulator's first activity by modifying the instructions of practice and allowing students to use the system to answer their doubts regarding passive transport solutions at different concentrations Table 3. We used the maximum concentrations of all $(20 \mathrm{mM}$ each) components and times with the largest porous membrane (MWCO 
Table 2. Baseline results on passive membrane transport during the first activity of the simulator

\begin{tabular}{|c|c|c|c|c|c|}
\hline Metabolite & mM & 20 MWCO & $\mathbf{5 0}$ MWCO & 100 MWCO & 200 MWCO \\
\hline CINa & 9 & $-*$ & 10 minutes & 10 minutes & 10 minutes \\
\hline & 20 & - & $11 \mathrm{~min}$ & $11 \mathrm{~min}$ & $11 \mathrm{~min}$ \\
\hline Urea & 9 & - & - & $16 \mathrm{~min}$ & $16 \mathrm{~min}$ \\
\hline & 20 & - & - & $18 \mathrm{~min}$ & $18 \mathrm{~min}$ \\
\hline Glucose & 9 & - & - & - & $36 \mathrm{~min}$ \\
\hline & 20 & - & - & - & $42 \mathrm{~min}$ \\
\hline Albumin & 9 & - & - & - & - \\
\hline & 20 & - & - & - & - \\
\hline
\end{tabular}

Abbreviations: MWCO: Molecular Weigth Cutt-Off, mM: mili Moles, $\mathrm{NaCl}$ : Sodium Chloride. * No results were obtained

Table 3. Analysis of the three molecules at different concentrations

\begin{tabular}{|c|c|c|c|c|c|c|}
\hline $\begin{array}{c}\text { Concentration } \\
(\mathbf{m M})\end{array}$ & $\mathbf{X}$ & $\begin{array}{c}\text { CINa } \\
\chi \begin{array}{c}\text { diffusion } \\
\text { rate }\end{array}\end{array}$ & $\mathbf{X}$ & $\begin{array}{c}\text { Urea } \\
\chi \text { diffusion } \\
\text { rate }\end{array}$ & $\mathbf{X}$ & \begin{tabular}{|c|} 
Glucose \\
$\begin{array}{c}\text { diffusion } \\
\text { rate }\end{array}$ \\
\end{tabular} \\
\hline 1 & 7 & 0.0024 & 12 & 0.0014 & 24 & 0.0007 \\
\hline 2 & 8 & 0.0042 & 13 & 0.0026 & 28 & 0.0012 \\
\hline 3 & 9 & 0.0056 & 13 & 0.0038 & 30 & 0.0017 \\
\hline 4 & 8 & 0.0083 & 15 & 0.0044 & 32 & 0.0021 \\
\hline 5 & 9 & 0.0093 & 15 & 0.0056 & 3.4 & 0.0024 \\
\hline 6 & 10 & 0.01 & 15 & 0.0067 & 3.4 & 0.0029 \\
\hline 7 & 9 & 0.013 & 16 & 0.0073 & 35 & 0.0033 \\
\hline 8 & 10 & 0.0133 & 16 & 0.0083 & 36 & 0.0037 \\
\hline 9 & 10 & 0.015 & 16 & 0.0094 & 36 & 0.0042 \\
\hline 10 & 9 & 0.0185 & 17 & 0.0098 & 37 & 0.0045 \\
\hline 11 & 10 & 0.0183 & 17 & 0.0108 & 38 & 0.0048 \\
\hline 12 & 10 & 0.02 & 16 & 0.0125 & 38 & 0.0053 \\
\hline 13 & 10 & 0.0217 & 17 & 0.0127 & 39 & 0.0055 \\
\hline 14 & 10 & 0.0233 & 17 & 0.0137 & 40 & 0.0058 \\
\hline 15 & 11 & 0.0277 & 17 & 0.0147 & 39 & 0.0064 \\
\hline 16 & 10 & 0.0267 & 18 & 0.0148 & 40 & 0.0067 \\
\hline 17 & 10 & 0.0283 & 18 & 0.0157 & 41 & 0.0069 \\
\hline 18 & 11 & 0.0273 & 17 & 0.0176 & 40 & 0.0075 \\
\hline 19 & 10 & 0.0317 & 18 & 0.0176 & 41 & 0.0077 \\
\hline 20 & 11 & 0.0303 & 18 & 0.0185 & 42 & 0.0079 \\
\hline
\end{tabular}

The achievement $\mathrm{NaCl} \geq 50 \mathrm{MWCO}$ pass through the filter while Urea and Glucose only were analyzed with the filters $100 \mathrm{MWCO} \geq \mathrm{y} \geq 200 \mathrm{MWCO}$ respectively. Abbreviations: mM: mili Moles, $\mathrm{NaCl}$ : Sodium Chloride.

200) were evaluated. We did not find differences between solutions with respect to the experiments suggested in the simulator guide $(\mathrm{p}=0.857)$, that is, that at the highest concentrations the filtering times of the solutions remain the same.

Similarly, the transport time was increasing as the concentration of the solution. Also the average diffusion rate (ADR) expressed as $A D R=\frac{\text { Solution }(\mathrm{mM})}{\text { Time }(\mathrm{seg})}$, suffered increases related to the concentration Table 3. The average transport was $9.6 \pm 1$ (95\% CI: 9 to 10.2) for sodium chloride $(\mathrm{NaCl}), 16 \pm 1.8$ (95\% CI: 15 to 17.9$)$ for urea, and $36.2 \pm 4.7$ (95\% CI: 33.4 to 39 ) for glucose.

In the second practical activity components and characteristics of the active transport were explored. This endergonic transport facilitates the transport of molecules against concentration gradient through protein carriers. We highlight the primary active transport (pumps protein, ATPases), the secondary active transport, and active transport across cell layers [15].

The activity proceeded censorship opened a dialogue on a number of topics related to biochemistry, biophysics, and biological membranes. The experiments allow to modify the number of pumps, the concentration gradients between two compartments, and the amount of selective competitors: three plausible concepts for biological evaluation of these issues. Likewise, this allowed discuss other systems cellular transport (such as the nuclear pores, the translocators of endoplasmic reticulum), and non-protein carriers (ionophore).

The third reviewed activity in this study was to demonstrate the membrane potential and conductivity cell electricity. The action potential is the energy required by a cell to change its composition and generating an electrical impulse. The initial conception of cell electricity was inadvertently recognized by the assistant physiologist of Luigi Galvani during dissection of an amphibian (frog), who later laid the foundation of the action potential.

This activity allowed educators explain the electrical properties of cells focusing on neurons. To investigate about single cells and their nerve conduction, allow to understand the action potential from the smallest to largest (Figure 1). In principle, differentiate electrochemical reactions and chemical reactions that occur at the cellular level, due to exchange between different ion concentrations. In simulation, queries about the transmission of nerve impulses to different concentrations of the major extracellular ions (calcium, chloride, sodium) and intracellular (potassium) were established.

\section{Second stage}

We surveyed 60 students studying HMI and the use weekly laboratory simulation PhysioEx, whose average age was 21.5 years (range 17 to 37 years) $(\mathrm{p}=0.02)$, and where the $71.4 \%$ (43 participants) were women. The $65.7 \%$ of students had $\leq 20$ years.

Thirty-seven percent of students said they always or almost always exists motivation during class while $38 \%$ said only "sometimes" or "never" the teacher motivates the students. When consulted on the use of techniques that promote student interaction, $28.1 \%$ indicated participate in this relationship, whilst $54 \%$ said they "never" or "sometimes" ( $\mathrm{p}=0.001)$. Survey about if class time is balanced between the theoretical and practical, $34.3 \%$ pointed out that is not suitable or is it with difficulty, compared to $40 \%$ who consider the time between them is "right" or "very suitable" (Table 4).

The PhysioEx was considered important by $35 \%$ of participants. About $75 \%$ of students said that this experience allowed their understanding about passive and active transport, but only $62 \%$ said that it allowed the understanding of membrane potential and electric transmission (Table 5). According to the 60 responses, 77\% think that the tool allowed guidance on the subject, although most experiment neglect by the teacher $(78 \%)(\mathrm{p}=0.088)$.

Forty-five percent said the main constraint was the language of the simulator, followed by the inaccessibility to the simulator in other areas as their homes or workplaces (20\%), and the unfamiliarity of teachers with PhysioEx (10\%); however, only $28 \%$ said they had difficulty with the use of the simulator. The third part of the survey showed that the vast minority of students was quiet with physiological simulation experience (35\%), 20\% experienced mastery, 15\% experienced anxiety, and $10 \%$ experienced other sensations. Among the advantages of the simulator, participants noted the graphics (45\%), ease-of-use (25\%), and the simplicity and organization software (15\%).

Finally, 55\% of students considered the experience as satisfactory, $60 \%$ considered unproductive resolution PhysioEx questionnaire, while $30 \%$ do not believe that experience to consolidate medical studies. 


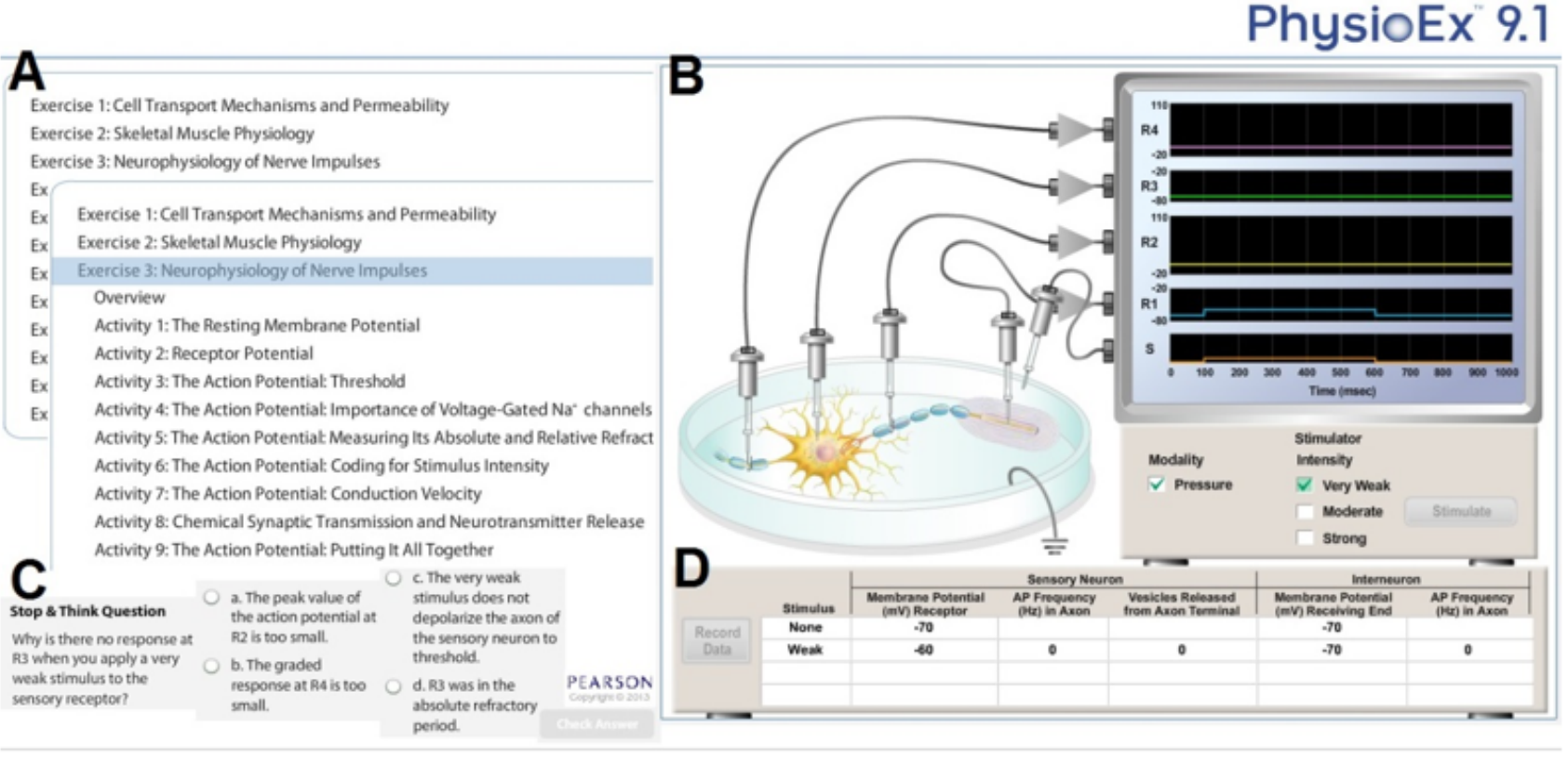

Figure 1. Virtual simulation systems PhysioEx v9.1. A. List of exercises and activities software. B. Activity of the action potential, where the amplitudes related to the amount of stimulus and evaluated in axonal and somatic portion of the neuron is explained. In vitro model. C. Self-assessment system software for physiological activity. D. Engraving system experiment results that can be exported in PDF format

This activity allows educators to explain the electrical properties of cells by focusing on neurons. The investigation of individual cells and their nervous conduction allows us to understand the action potential of the smallest to the largest. In principle, differentiate the electrochemical reactions and chemical-reactions that occur at the cellular level, due to the exchange between different ionic concentrations. In practice with the simulator allowed to establish questions about the transmission of nerve impulses at different concentrations of the main extracellular (calcium, chloride, $\mathrm{Na}+$ ) and intracellular (potassium) ions. When the nerve cell is at rest, it is not in a neutral state, there is an electro-voltage that diffuses with the difference of intracellular and extracellular electrical potential, allowing the transmission of the message to last. Undoubtedly, the membrane potential can be explained by making use of common cases, such as batteries and their positive and negative terminals where the electric potential causes electrons to be shared between both sides.

Table 4. Summary of results of the second stage of evaluation - Questions block I. Data in $\mathrm{n}(\%)$

\section{Questions}

1. Does your teacher encourage the class to arouse interest in students?

2. Does your teacher propose techniques that promote student interaction?

Never

$7(11.4)$

$7(11.4)$

$7(11.4)$

. Is class time well balanced for the theory and practice?

Total

Table 5. Summary of results of the second stage of evaluation - Questions block II. Data in $\mathrm{n}(\%)$

\begin{tabular}{|l|c|c|}
\hline Questions & Yes & Do not \\
\hline Has the simulation in the PhysioEx been relevant for you? & $26(42.9)$ & $34(57.1)$ \\
\hline Was it a tool guidance on the subject? & $41(68.6)$ & $19(31.4)$ \\
\hline Has it allowed the understanding of passive transport? & $46(77.1)$ & $14(22.9)$ \\
\hline Do you experience neglect by the teacher? & $19(31.4)$ & $41(68.6)$ \\
\hline Has it allowed the understanding of active transport? & $39(65.7)$ & $21(34.3)$ \\
\hline Has it allowed the understanding of membrane potential? & $39(65.7)$ & $21(34.3)$ \\
\hline Do you think it helps to consolidate medical studies? & $27(45.7)$ & $33(54.3)$ \\
\hline Did you have difficulties using the simulator? & $33(54.3)$ & $27(45.7)$ \\
\hline Has the questionnaire resolution been useful for your learning? & $43(71.4)$ & $17(28.6)$ \\
\hline Has the experience been satisfactory for you? & $29(48.6)$ & $31(51.4)$ \\
\hline Does the language was a limitation to understand its contents? & $45(74.3)$ & $15(25.7)$ \\
\hline Total & $387(58.6)$ & $273(41.4)$ \\
\hline
\end{tabular}

No significant difference was found between the genres $(\mathrm{p}=0.883)$ and between groups practice $(\mathrm{p}=0.514)$.

\section{Discussion}

In this study, we describe the scope and limitations of each simulation with PhysioEx v9.1 as programming skills of HMI course where the student interrelates with basic cell physiological processes

\begin{tabular}{|c|c|c|c|}
\hline Sometimes & Regularly & Usually & Forever \\
\hline $15(25.7)$ & $15(25.7)$ & $7(11.4)$ & $15(25.7)$ \\
\hline $27(45)$ & $10(17.1)$ & $7(11.4)$ & $10(17.1)$ \\
\hline $14(22.9)$ & $15(25.7)$ & $7(11.4)$ & $14(22.9)$ \\
\hline $56(31.6)$ & $40(22.6)$ & $21(11.9)$ & $39(22)$ \\
\hline
\end{tabular}

in a technological environment between teacher-software-student. However, this system has remarkable limitations presented by the students who are, or should be, a challenge for teachers and training institutions.

This promising start of the use of educational innovations will generate a disruptive change in the national medical education promoting the prolific use of the current technological environment in young people [16]. Apparently many of the educational reforms in various parts of the world are transformed with varying degrees of attainment traditional physiological-anatomy medical practice in an educational hybrid model [17-19].

Traditional medical education faces a challenge by incorporating technologies more and more automations. These have proved useful in several educational systems, reducing costs, bringing practicaltheoretical repetitions at the mercy of users, reducing fatigue teacher, connecting users providing opportunities to new strategies for teaching and learning never before possible $[20,21]$. The new curriculum model C21 of New York University is an example of this [22].

The increasing change and the modern challenges the traditional model of medical education, coupled with the dramatic changes in health-care is promoting the development of disruptive projects 
in medical education reform globally. In Peru, however, lack the curricular uniformity between private and public universities, policy neglect to regulate the entry and acceptance of students in medical schools, and problems during clinical practice and scientific research emerge as permanent challenges sectors actors involved must confront [18,23-25].

Our findings have shown that the simulator allows effective education against traditional model of explanatory dialogue with monological approach, which has lacked for decades of other representations beyond drawn on blackboards, explained on corpses or by projection of still images. We do not propose to dismiss these production models of teaching that preceded the great medical achievements and discoveries over the past two centuries, but we intend to point out that medical simulation opening a new way of learning that could change facets teaching based in, i.e. the imperishable memorization towards an organized visual learning with technological devices and tools.

Thus, we believe that remains imperiously integration of teaching with organs, tissues and real cells, but with the additional aid of simulation that allows knowing structures poorly evaluated, shortly available whenever required, thereby avoiding large investments, availability of large spaces equipped with the perennial presence of a teacher, and the risk of damaging anatomical models, often unit.

The major $(>65 \%)$ users of PhysioEx were technology natives. Recently, it has been reported that $\sim 40 \%$ of these students had difficulty with simulating clinical interview, but $99 \%$ rated the experience as satisfactory [16]. Our data show that more than half of students are dissatisfied with the physiological simulation; may be due to a combination of factors such as limited lessons hours, deficient involvement of teachers, etc.

The teaching curriculum structure in HMI course, and other topics, should be carried out considering the characteristics of this new generation $[10,26]$. For example, $30 \%$ of student dismissed the contribution of the consolidation simulation-studies, $~ 50 \%$ said it was not relevant, and $60 \%$ considered unproductive resolution PhysioEx questionnaire. It must reflect on these concepts since the success of a medical training program depends on the quality of students and professionals incisors human health.

For instance, during the practice of passive membrane transport, must extend the educational dialogue with the use of MWCO, allowing explore the utility and selectivity of the size of filters for dialysis, as well as understand the characteristics of the renal threshold and its relationship with type II Diabetes Mellitus. The average diffusion rate (ADR) is another component that allows the argument of other issues such as the Law of Graham and Fick, and diffusion-weighted imaging [27].

Another example is related to the albumin that being a large (135 amino acids, $13,950 \mathrm{~g} / \mathrm{mol}$ ) molecule was not traversing the membrane or be transported between compartments. The academic achievement, refers to the understanding that the Albumin requires active transport, energy expenditure, and a recognition system for intramembrane diffusion.

Our analysis indicates that over $70 \%$ of students understand the physiology of passive and active membrane transport. In this context, understanding e.g. the semi-permeability, balancing Nerst/Goldman, etc., should be indicators of these issues to be properly assessed.
Our findings indicate that $38 \%$ of students had difficulty in understanding the membrane potential and electric transmission. Since the treaties of Luigi Galvani to advances in contemporary neuroscience and neurology are two important components of medical training that should be addressed in the current technological and visual-integrative framework. Since these topics in turn represent the most difficult topics for students of HM as detailed our findings and other studies [21,28,29], medical education programs should devote their efforts to strengthen and improve their schemes in an organized teaching university, of medical specialties, and post-graduate in neurosciences in particular, and in medicine and Life Sciences in general. Using new approaches such as sociobiological informational theory, or online programs that provide prestigious universities could be new educational alternatives.

Hence, these educational methods must be developed using available resources and technology development as an ally, as happens in most European countries and the US medical training [18,20,3033]. Possessing a simulator in a virtual classroom as a teaching tool for teachers ally explains cosmopolitan technology and provides unused opportunities for students under proper management curriculum and educational approach.

Finally, then we put forward the advantages and reticence simulator. Among the first, we mean the possibility of internships in physiology without the use or prejudice animals, perform complicated tests using simple instructions, step-by-step, with malleable components although limited, with high data variability in the results reflects more realistic outcomes that students were in a real laboratory experiment, and the possibility that students collect data and manage virtual lab reports and documents. Our findings showed that students identified as main advantages graphics, ease of use, simplicity, and organization software.

The main limitation of using this software was the language English (45\%) that reflected the population of Peru limitation [33,34]. Other aspects were that this simulator is not an open source technology and hence students (20\%) were unable to access this from other technology platforms. Often we must emphasize that $10 \%$ of students reported that teachers were not familiar with the activities of the simulator, which in turn is limited by each experiment activities and these not be extended at libitum.

\section{Limitations}

The main limitation was the sample size used in this study. Another limitation was that only one semester students were evaluated. These should be points of interest for future evaluations.

\section{Conclusions}

The evaluation of the simulator allowed knowing the main advantages and limitations of PhysioEx v9.1 within the new educational experience virtual simulation of Human Medicine students at an Universidad Norbert Wiener in Peru.

\section{References}

1. United Nations (2017) The sustainable development goals report. United Nations Publications, New York.

2. Moya-Salazar J, Rojas-Zumaran V (2017) Trends in Human Papillomavirus research in Latin America and in high-income countries. Rev Col Obst Gin 68: 128-134.

3. Organization for Economic Cooperation and Development (2018) Competencies in Latin America analysis of PISA 2015. Madrid: Santillana Foundation.

4. Wolff L (2007) The costs of student assessments in Latin America. Inter-American Dialogue, Educational Revitalization in the Americas, Washington, DC. 
5. World Bank (2007) Toward high-quality education in Peru. Standards, accountability, and capacity building. The International Bank for Reconstruction and Development, Washington, DC.

6. Fundación Santillana (2016) Building Quality Education: A Pact with the Future of Latin America. Buenos Aires, Argentina: Commission for Quality Education for All, Fundación Santillana.

7. Bustamante RC (1985) Ethics, medicine and society. Lima: IBM, Marshal Miller.

8. Association of American Medical Colleges (AAMC) (2017) Table B-2.2: Total graduates by U.S. Medical School and sex, 2012-2013 through 2016-2017.

9. Duvivier RJ, Boulet JR, Opalek A, van Zanten M, Norcini J (2014) Overview of the world's medical schools: an update. Med Educ 48: 860-869.

10. Palfrey J, Gasser U (2018) Born digital: understanding the first generation of digital natives. New York: Basic Books.

11. Prensky M (2001) Digital Natives, Digital immigrants. Bingley: MCB University Press.

12. Kemmis S (1977) Atkin R, Wright E. How do students learn? Norwich: Working Papers on Assisted Learning. Centre for Applied Research in Education, University of East Anglia.

13. Squirres D, McDougall A (1997) How to choose and use educational software. Madrid: Morata editions.

14. Gobierno de Navarra (2009) Guide to measure satisfaction regarding the services provided. Navarra: Service Letters. Evaluation and Quality. Government of Navarra.

15. Hall JE (2016) Guyton and Hall Textbook of Medical Physiology. 13th [Edn]. Elsevier, New York.

16. Iza SA, Mendoza-Arana P, Choquehuanca-Vilca V (2017) Simulated medical consultation as a learning experience for students of the first cycle of human medicine at Norbert Wiener University. Rev Inves Univ Norbert Wiener 6: 11-16.

17. Arantes M, Barbosa J, Ferreira MA (2017) Differences in the students' perceptions on the teaching of neuroanatomy in a medical curriculum organized by disciplines and an integrated medical curriculum. Acta Med Port 30: 26-33.

18. Dezee KJ, Artino AR, Elnicki DM, Hemmer PA, Durning SJ (2012) Medical education in the United States of America. Med Teach 34: 521-525. [Crossref]

19. White T (2011) Body image: Computerized table lets students do virtual dissection.
20. Torres K, Torres A, Pietrzyk L, Lisiecka J, Błoński M, et al. (2014) Simulation techniques in the anatomy curriculum: review of literature. Folia Morphol (Warsz) 73: 1-6.

21. Wah RM (2015) 3 ways technology is changing medical education. American Medical Association Education.

22. New York University (2012) Medical students at NYU School of medicine use interactive virtual 3D cadaver. NYU Langone Health.

23. PMM Astudillo (2016) Specific work benefits for medical interns: Proposal for a bill [Thesis]. Lima: Law School, University of Lima.

24. McManus IC, Powis DA, Wakeford R, Ferguson E, James D, et al. (2005) Intellectual aptitude tests and levels for selecting UK school leaver entrants for medical school. BMJ 331: 555-559. [Crossref]

25. Ministry of Economy and Finance (2002) Supreme Decree No. 020-2002-EF. They set monthly compensation for interns of Human Medicine and Dentistry. Lima: MEF / MINSA.

26. Denegri MA (2014) Polymathia Lima: Inca Garcilaso de la Vega University.

27. Weiss TF (1996) Cellular Biophysics: Transport. Cambridge: MIT Press.

28. Hall S, Stephens J, Parton W, Myers M, Harrison C, et al. (2018) Identifying medical student perceptions on the difficulty of learning different topics of the undergraduate anatomy curriculum. Med Sci Educator 28: 469-472.

29. Contreras-Pulache H, Espinoza-Lecca E, Sevillano-Jimenez (2018) Notes on the evaluation of the work of Pedro Ortiz Cabanillas and his Information Sociobiological Theory. Rev Per Med Exp Salud Publica 35: 699-706.

30. Dent J, Harden RM, Hunt D (2017) A Practical Guide for Medical Teachers. Ámsterdam: ElSevier.

31. McManus IC (2016) Hunt promises 25\% more medical students in 2018. Br Med J 355: i5480.

32. Cruess RJ, Cruess SR, Boudreau JD, Snell L, Steinert Y (2014) Reframing medical education to support professional identity formation. Acad Med 89: 1446-1451.

33. Smith O (2017) Mapped: Where to go if you can't be bothered to learn the language. The Telegraph.

34. British Council (2015) English in Peru. An examination of policy, perceptions and influencing factors. Education Intelligence.

Copyright: (C2019 Moya-Salazar J. This is an open-access article distributed under the terms of the Creative Commons Attribution License, which permits unrestricted use, distribution, and reproduction in any medium, provided the original author and source are credited. 